\section{EDUCACIÓN, SÍMBOLO, TACTO. MÁS ALLÁ DEL MODELO INSTRUMENTAL EN LA PEDAGOGÍA}

\author{
Marcos Santos Gómez \\ Departamento de Pedagogía \\ Universidad de Granada \\ masantos@ugr.es
}

Cómo citar este artículo/Citation: Santos Gómez, M. (2013). "Educación, símbolo, tacto. Más allá del modelo instrumental en la pedagogía". Arbor, 189 (763): a073. doi: http://dx.doi. org/10.3989/arbor.2013.763n5010

Recibido: 14 enero 2013. Aceptado: 22 julio 2013.

RESUMEN: Argumentamos que las teorías pedagógicas basadas en epistemologías modernas de tipo racional instrumental no son totalmente adecuadas para abordar la educación. Esto es así porque el hombre y la relación educativa manifiestan una enorme complejidad y una profundidad que ha de captarse interpretativamente, con una inteligencia hermenéutica o táctil, que se relaciona con la phronesis griega, o sabiduría práctica. Es preciso un esfuerzo por comprender lo que no puede ser jamás plenamente comprendido ni iluminado, como algo de naturaleza simbólica, ambigua, oscura, singular, contingente. La razón científica que pretende iluminar plenamente y dominar resulta un medio ciego y hostil a los matices de esta realidad humana que llamamos educación.

PALABRAS CLAVE: Hermenéutica; Símbolo; Phronesis; Razón; Filosofía de la educación; Educación.

\section{EDUCATION, SYMBOL, TACT. BEYOND THE INSTRUMENTAL MODEL IN PEDAGOGY}

Copyright: (C) 2013 CSIC. Este es un artículo de acceso abierto distribuido bajo los términos de la licencia Creative Commons Attribution-Non Commercial (by-nc) Spain 3.0.

ABSTRACT: I argue that the pedagogical theories based on modern epistemologies of instrumental reason are not entirely suited to studying education. This is due to the huge complexity and depth of man and education, which needs to be captured interpretively, with a hermeneutic or tactile intelligence, which is the Greek phronesis, or practical wisdom. This requires an effort to understand what can never be fully understood or illuminated, considered something symbolic, ambiguous, dark, singular, and contingent. Scientific reasoning, which aims to fuIly illuminate and master it is taking the wrong approach and one that is hostile to the nuances of this human reality called "education".

KEYWORDS: Hermeneutics; Symbol; Phronesis; Reason; Philosophy of education; Education. 


\section{INTRODUCCIÓN: HACIA UNA ALTERNATIVA AL MODELO INSTRUMENTAL}

En la actual investigación educativa debemos plantearnos si lleva a buen puerto el paradigma epistemológico instrumental con su clásico desdoblamiento entre una razón teórica que piensa y abarca desde un punto privilegiadamente neutro ese otro lugar llamado "práctica". O sea, se trata de replantear el papel de la razón en la forma en que esta es utilizada asépticamente para analizar una realidad objetivada. Este asunto es hoy un tema candente ya que este paradigma típicamente moderno subyace al modelo de las competencias, que puede venir a ser, en sus distintas versiones, el del sujeto capacitado para operar en un mundo a su disposición, el del sujeto que adquiere técnicas para desenvolverse en un medio que lo desafía y es capaz de afrontar los problemas planteados por la supervivencia en dicho medio.

Filosóficamente, esto se vincula con un modelo instrumental de razón en el que esta es un medio para conseguir fines, una suerte de útil que emplea el sujeto para sobrevivir y medrar en el medio ejercitando su dominio sobre el mismo. Tal vez en el discurso de las competencias exista un abanico de posibilidades mayor que el representado por las posibilidades específicas contenidas en una mera razón instrumental y técnica objetivante. Pero si no fuese así, estaríamos ante una nueva versión del clásico mal de la modernidad ya tantas veces diagnosticado, consistente en una reducción de la razón que obliga asimismo a una reducción del sujeto y, como en toda reducción, a una serie de olvidos, mutilaciones e invisibilizaciones de distinta índole, que se han señalado abundantemente en la historia de la filosofía contemporánea. La dialéctica de una razón instrumental, que tiende a ejercer su dominio contra el propio sujeto que se vale de ella para dominar el mundo, sería uno de los señalados peligros (Horkheimer y Adorno, 2001).

Por un lado, esta reducción epistemológica muestra, a mi juicio, un déficit en la comprensión del hombre, y por otro lado, también implica un empobrecimiento existencial, en la medida en que como indicaba el subtítulo de una conocida obra de Adorno, la vida resulta dañada (Adorno, 2003). De hecho, en no pocas ocasiones desde la propia pedagogía se ha venido criticando los excesos de un modelo empírico explicativo de corte restringidamente positivista en el estudio científico de la educación (Gordillo, 1992, 182-184). Como afirma Pérez Luna con clarividencia: "La pedagogía que se sometió a las directrices de la razón instrumental atentó contra la libertad, se hizo pedagogía silenciosa, pedagogía sin voz, por ella hablaba un proyecto de reducción del hombre y de toda idea emancipatoria" (Pérez Luna, 2003, 94).

Un recomendable artículo de José Antonio Zamora (2009) diagnostica certeramente lo que está ocurriendo en el mundo de la enseñanza, teniendo como referencia la filosofía de Adorno. "La formación reducida a cualificación profesional se orienta unidimensionalmente a la promoción de aquellas capacidades y talentos que prometen una utilidad económica actual. Y las instituciones educativas son evaluadas por el mismo criterio, es decir, según sirvan o no al proceso productivo, a aumentar la competitividad de la economía o a mejorar las oportunidades de ingreso y ascenso de quienes pasan por ellas" (Zamora, 2009, 39). Suscribimos plenamente los temores de Zamora de que "La iniciativa individual y la libertad de investigación puede verse muy mermada por la tendencia observable en esa estructura a la estandarización y el control, la planificabilidad y la comparabilidad" (Zamora, 2009, 41). La constante exigencia de cumplir con los requisitos del mercado laboral y de una preparación técnica frenética para no sufrir la exclusión, tiene, afirma Zamora, un efecto devastador: "supone el triunfo de la ideología economicista neoliberal en el plano de la automercantilización de los individuos, que han de estar dispuestos a relativizar sus rasgos personales o incluso a no formar ninguna personalidad en el sentido clásico para adaptarse flexiblemente a las condiciones rápidamente cambiantes del mercado" (Zamora, 2009, 43).

Frente a este somero diagnóstico, creo que la pedagogía debería cumplir una función de resistencia a estas dinámicas mercantilistas que echan mano de modelos instrumentales de racionalidad. De hecho, la pedagogía sería más útil si no se centrara tanto en ofrecer respuestas, sino en interrogar(se), en sospechar de sus propias explicaciones y en introducir elementos discrepantes y marginales en su discurso. Así cabría entender una pedagogía y por ende una escuela y universidad comprometidas con la sociedad, en la medida en que actuaran como instancias críticas.

En este trabajo deseo traer a colación una alternativa a este paradigma instrumental de la modernidad instalado implícitamente en parte de la pedagogía actual. Para ello hay que atender a la filosofía, como propone a los educadores el profesor Joaquín Esteban (2002). Éste expone una concepción de la pedagogía inspirada en la filosofía hermenéutica de Gadamer que, entre otras implicaciones, permite una conexión entre teoría y práctica en la pedagogía, como se ha señalado en algún otro artículo (VanderVen, 2009). 
Recordemos que el pensamiento de Gadamer (2002 y 2003) es un intento de, como se ha dicho, "urbanizar la provincia heideggeriana", es decir, dotar de un cierto contenido lo que en Heidegger queda sólo en el aire como mera "facticidad". Se trata de ese fondo desde el que el Dasein emprende su autocomprensión y la comprensión de aquello que se revela oblicuamente, impresentemente presente, como es el Ser. El hombre, sujeto o, más propia y heideggerianamente, " $D a$ sein", es el pastor del Ser, el ente que trata con el Ser, en cuyo trato con el Ser le va su ser. Así, Heidegger retrotrae la filosofía (y la existencia) a un sobrecogedor nivel ontológico, a una sima, en la que Gadamer halla que la interpretación y la auto-comprensión se hace como inmersión en tradiciones que dotan de horizontes de sentido, de fines, de perspectivas.

El hombre está condenado a carecer de los antiguos fundamentos sólidos de un Ser descrito como un ente que, en el platonismo, explicaba y orientaba la existencia del propio hombre. Ya no hay más que una sucesión de relatos, historias que ciertamente nos explican y orientan pero débilmente, o sea, con un cierto velo, con un aire difuso, veteado de nada y de incertidumbre.

Obviamente, la ontología débil, entendida como hermenéutica del sujeto y relacionada con una existencia que se auto-interpreta y que se sitúa en un contingente contexto (comunitario), rechaza la epistemología que era capaz de establecer sentidos y órdenes firmes en el mundo y en lo humano. Esta epistemología, que puede funcionar bien para la ciencia, es un peligro, por reduccionista, si la intentamos aplicar a la comprensión del hombre-sujeto y de la existencia. Sencillamente, la epistemología basada en un método apriorístico que analiza, establece leyes y deduce, no puede decir nada sobre la existencia. Pero todavía más, la propuesta del profesor Joaquín Esteban (2002) es que dicha epistemología y dicho paradigma moderno tampoco valen para educar de manera efectiva o por lo menos para entender qué hacemos cuando educamos. Este autor se sitúa en un término medio, entre el mencionado racionalismo fuerte de la modernidad o del platonismo y otro exceso: el relativismo.

Según Esteban (2002), el educando iría insertándose en su medio al ser educado por este mismo medio o por el educador-mediador, pero nunca como agente capaz de distanciarse y dominar al modo instrumental su propio medio lejos de todo prejuicio. Educarse es impregnarse de un entorno, de una atmósfera que nutre las preguntas y orienta el pensamiento, previa a todo uso instrumental de la razón y a toda apuesta por una epistemología de raigambre cartesiana. Así que el profesor Joaquín Esteban valora el papel de la memoria en la educación, pero no una memoria entendida como instrumento técnico, como cúmulo de datos e instrucciones, sino como ese entorno o tradición en el sentido que estamos indicando. Educarse sería tomar contacto con esa materia, hacerse cada vez más uno con ella y desde ella hacer brotar las preguntas y la teoría. Toda toma de distancia reflexiva presupone esta previa hermenéutica, como tarea anterior de comprensión y de adquisición-construcción del sujeto. En las palabras empleadas por Esteban, educar sería entrar en contacto con la cultura y con la historia como algo complejo, inasible del modo reduccionista con que trata de hacerlo el paradigma moderno de comprensión de la historia o de la pedagogía. Esto implica que el educador debe ante todo desarrollar un estar en sintonía, un "talante" o "tacto" pedagógicos, no tanto como empleo de métodos a priori o de técnicas didácticas, sino como diálogo con el educando y el medio común (cultura, historia) que arranque siempre a posteriori, tras la inmersión en la práctica.

\section{EL TACTO PEDAGÓGICO}

La palabra educación nos remite a un tiempo humano, concreto, dual; a un acontecer que se nos impone en nuestro trato con un Otro que se cuela en nuestro mundo, en nuestra firme seguridad, en nuestras certezas. El niño introduce un más allá, un futuro de posibilidades y novedad-natalidad (Bárcena, 2002), y simultáneamente un presente singularísimo.

La relación previa a todo estudio teórico emprendido por la pedagogía, entendida como ciencia o reflexión que los padres establecen con los niños, es una relación de cuidado, de acogida, de receptividad. La cara del niño con sus grandes ojos exige al adulto que vele por él y de su rostro emana, como diría Levinas, una suerte de imperativo ético que siendo universalizado y extendido al género humano, se manifiesta en el mandato "no matarás" (Levinas, 1977). Es una ley sin palabras, porque se alza previa a la palabra creadora, como condición de la misma. Ésta es la teoría a la que apunta la cara del niño, la obligación de velar por su vida y, todavía más, por su futuro. Cuando se está con un niño se está también con su futuro; un futuro propio al que sin embargo no se debe sacrificar el presente. En el niño, de hecho, se concretizan dos tiempos: futuro y presente, el futuro por hacer y el singularísimo instante. Ambos inciertos y requeridos de protección y cuidado. 
Una consecuencia de este enraizamiento de lo educativo en lo más personal y concreto del niño es que nunca deberíamos perder de vista lo concreto en la reflexión teórica o en la enseñanza universitaria que se da a futuros maestros. Me refiero a que, aunque se enseñen métodos, didácticas, técnicas de enseñanza, hay una cualidad esencial que es en sí lo más específicamente pedagógico o educativo, como un tacto. Es una sensibilidad que consiste en la buena lectura que uno hace de ese momento práctico, de ese ambiente concreto, de esa situación de educación y del estado del niño. Hay que advertir que la psicología ayuda pero eso no implica que reduzcamos este tacto al conocimiento y método específicos de la psicología. Es más que eso, porque estamos hablando de la capacidad de ser demandado por la llamada que es en sí el Otro y de preocuparse por su presente y su porvenir. Es un ponerse en la situación de hacerse cargo del destino del niño como persona que va, que se hace, que está siendo, que requiere un porvenir y que tiene unas posibilidades por conquistar. Es responsabilidad. Hay en esta relación educativa un obvio desnivel, porque el educador tiene autoridad, auctoritas, ganada día a día y concedida por el niño (la autoridad del adulto se la da el niño y el adulto se la gana).

Estas ideas son desarrolladas, a partir de ejemplos prácticos, con imágenes concretas, por el catedrático de educación de origen holandés Max van Manem (1998). Su objetivo es abandonar los abundantes enfoques psicologistas en pedagogía y acudir a una visión más próxima a la filosofía, de raigambre hermenéutica y fenomenológica, en la medida en que se elude la ontología de lo factual (positivismo) para ir, por el contrario, a lo fáctico, al mundo de la vida, a la inmersión en el contexto difícilmente captable con la mirada positivista y los instrumentos del psicólogo. No hay un rechazo, por supuesto, de la psicología con sus métodos habituales, sino un adentrarse más hondo de lo que resulta posible para ella con dichos métodos. De este modo, el pedagogo de formación o inspiración filosófica se sumerge en ese tiempo que he calificado al principio como "humano", "concreto", "dual", ese lugar singular en el que hay que situarse y estar para comprender el proceso educativo. Advirtamos que ello no se opone a la disposición de una cierta racionalidad u objetividad dada sobre el terreno, sobre la marcha, similar a la del actor que sopesa su actuación mientras hace su papel en la obra de teatro. Así se ha destacado no sólo por Manem sino por algún otro autor (Clark, 2005).

Hay, por tanto, razón y captación racional de lo que ocurre, pero no al modo objetivante propio de la cien- cia positivista que, según Manem, no llega al todo que constituye el proceso o acto educativo. De hecho, el educador reflexiona, pero lo hace inmerso en su tarea y a partir de lo que le ocurre en ella. Hay una prioridad de lo práctico en el pensamiento pedagógico, porque la pedagogía es un saber teórico que es sin embargo eminentemente práctico (es "teoría práctica" podría afirmarse, aunque suene contradictorio).

El conocimiento pedagógico se encarna en lo que Manem llama "tacto pedagógico" que es una suerte de sensibilidad situacional, dada en una situación educativa, de la que se extraen consideraciones para una acción prudente, equilibrada, eficaz, encaminada a obtener un bien en el niño. Es lo que para Manem suple a las técnicas cuando estas son entendidas en un sentido de razón estratégica. El tacto no es una racionalidad estratégica, de medios-fines, que pueda planificar en función de unos objetivos claros, aunque presuponga una cierta reflexión en la inmersión práctica y previa, anticipadora. Lo bueno que espera obtenerse para el niño viene dado por una tradición y por ejemplos anteriores que están en la memoria (en gran parte inconsciente y corporal) del maestro. De hecho, el modo en que se aprende y ejercita el tacto es mediante ejemplos y situaciones únicas, que es como, precisamente, estructura su libro Manem (1998), como un enorme cúmulo de elocuentes ejemplos que expresan sin definiciones cerradas lo que es el tacto, mostrando el tacto en acción. Vemos que lo que se pone en marcha es una especie de inteligencia interpretativa, intuición moral práctica, sensibilidad y receptividad hacia la subjetividad de los niños y capacidad de improvisación en el trato con ellos. Debemos resaltar, en este sentido, que recientemente se ha publicado un artículo que describe una aplicación creativa del modo fenomenológico de comprensión interpretativa y "táctil" de la realidad por parte del educador en un caso concreto, propuesto por Manem, que puede ser leído y valorado paralelamente a lo que aquí vamos desarrollando a un nivel más especulativo (Ayala, 2011).

La razón objetivante y técnica se nos torna impotente para comprender la pedagogía en última instancia porque lo que sucede en una clase resulta casi imposible que sea descrito en sus términos, porque resiste toda conceptualización. Es decir, si intentamos describir o explicar lo que sucede en el aula con la distancia propia de la reflexión convencional, ya no estamos en el nivel propio de la situación pedagógica y no podemos captar su tiempo. Se requiere una cierta reflexión semejante a una consciencia, dice Manem, a 
un estar consciente en dicha situación. La clase, desde la perspectiva del profesor, es una "consciencia" que sin llegar a ser plenamente distancia reflexiva, ya que se halla inmersa en lo que allí está sucediendo, es un continuo anticipar, ajustarse, modificar, que podemos llamar, acaso en un sentido muy amplio, "diálogo". Se trata de un pensamiento el que el profesor desarrolla durante la clase, pero un pensamiento concreto, móvil, en acción.

Para lograr esta habilidad o sensibilidad, se requiere una inmersión previa en los ejemplos, en la praxis educativa, en la tradición y por supuesto una cierta reflexión tanto a posteriori como anticipativa. Esto último es lo que se desarrolla en una programación, es decir, una anticipación de las posibles situaciones en un aula, un curso de una asignatura o materia, (que en los niveles más superiores de la enseñanza reglada constituiría un tercer elemento fundamental, de los que participarían en el tiempo pedagógico). De hecho, como ocurre en el teatro o la música, el guión hay que prepararlo bien y cuanto más concienzudamente preparado esté, la improvisación requerida por la flexibilidad consustancial a lo contingente y temporal de la situación pedagógica será más justa, el tacto pedagógico funcionará mejor. Esa suerte de inteligencia práctica que ya algunos griegos describieron como Phronesis (Aristóteles), como una reflexión veloz, sobre la marcha, en la doxa, inmersa en la vida, requiere, en una aparente paradoja, una previa estructuración y entrenamiento ${ }^{1}$.

\section{LO SIMBÓLICO COMO SUSTRATO DE LO EDUCATIVO}

Como hemos señalado, la educación implica una acción difícilmente conceptualizable porque entronca con la compleja realidad humana, con la realidad humana educativa que es una re-creación constante. Pero no confundamos lo nuevo con lo nacido de la nada y el propio Manem aludía al papel de mediador que hace el profesor, entre una tradición y el niño. El niño es niño, como en general el hombre es hombre por mediación de una influencia, siendo dicha influencia lo que propiamente denominamos "educación".

Esa invisible atmósfera, que sin embargo resulta activamente operante, ese hálito de vida, que nos rodea e impregna, entrañablemente, viene exhalado por quienes apenas son ya polvo. Ese fondo es el que el profesor Joan-Carles Mèlich investiga en alguno de sus trabajos (2004a). Un fondo que no puede ser alcanzado con armas conceptuales porque está más allá de lo conceptual. En palabras de Mèlich, se trata de un universo simbólico y no sígnico que, contra lo que pretendiera Freud, no puede ser interpretado en un sentido positivista. Uno debe sumergirse en él, como en la literatura o en los mitos, y probar hermenéuticas aproximativas. Mèlich (2004a) valora, sobre todo, la hermenéutica emprendida por Girard, que encuentra fructífera en cuanto clave para entender acontecimientos en el aula. Se trataría de estudiar la escuela y la educación en general como lo haría un antropólogo que se sumergiera en la vida de los otros, capaz de trastocar su mundo propio y desdoblarse viendo con los ojos de los otros.

En realidad, filosóficamente nos ubicamos en lo iniciado por el Husserl tardío, con su noción de "mundo de la vida", por la cual entendía ese sustrato precientífico, preconceptual, dador de sentidos, de horizontes, previo a toda significación y a todo lenguaje, en el que nos hallamos inmersos de hecho, arrojados, de algún modo arrastrados, como en una corriente, y que determina contextualmente, no causalmente, a modo de atmósfera el mundo de la claridad que llamamos ciencia, razón o verbo.

La educación es también algo simbólico, ambiguo, referido a esa penumbra incierta. La palabra que podemos emplear además, conectando con la perspectiva de Gadamer, es "tradición". Hay pues una tradición, pero por tradición debemos entender una cosa antes oscura que clara, y, siguiendo a Mèlich, antes simbólica y mítica que sígnica y conceptual. No se trata de un régimen de ideas, sino de palabras en cuanto condensaciones o campos de connotaciones, constituyendo aperturas antes que cierres de significados. Es el mundo del poeta. Un mundo de creación, amplitud y ramificaciones. Un mundo que se desdobla, de espejos que se reflejan en otros espejos. Eso es la tradición. En el fondo una nada. Pero una nada que aunque se sustenta en una nada, nos da la sensación de ser algo.

Pero necesitamos creer que somos algo. Y para creer eso necesitamos las complejas construcciones y los espejismos de la tradición de símbolos que se desdoblan y que en el fondo, lo decía Borges y parece que Girard apunta a lo mismo según Mèlich, llegan a unos pocos arquetipos. Ese origen, ese centro, esos centros, nos dan la sensación de estar en algún sitio, de saber dónde estamos, de conocer a dónde nos dirigimos. Mèlich lo evoca y también alude al drama de nuestra época en la cual los centros ahora parecen ser muchos.

Esta tensión vertebra la escuela. La necesidad de un centro del laberinto. Borges decía en alguna entrevis- 
ta que el horror no era que en el centro de todo hubiera un infierno o un dios malo, sino que sencillamente no hubiera centro. Eso es lo que peor puede soportar el hombre y por eso mismo creamos mitos y somos simbólicos. Esa es nuestra noche y nuestra penumbra, que, según Mèlich, gran parte de la pedagogía ha eludido. Él reivindica un reencuentro con esta naturaleza simbólica nuestra, que puede hallarse en la literatura fácilmente, en grandes novelas y autores (Mèlich, 2003). Todo esto no supone una vuelta a un extremo irracionalista, advierte, sino que asumimos otro modo de razón, otra racionalidad, una razón simbólica que busca pensar connotativamente, pensar lo ambiguo, lo inseguro, lo incierto, de un modo vibrante. Se trata de que ampliemos nuestra noción de razón, de manera que abordemos las zonas de la realidad que, con el modo restringido positivista, debíamos dejar de lado.

Ahora se trata de asumir que en efecto somos en gran parte seres simbólicos que no pueden vivir sin relatos, relatos que nos motivan e implican afectivamente, compuestos de símbolos, con ritos, de mitos al fin y al cabo. Creo que ese subsuelo está y estará siempre y no pertenece como muy bien recuerda Mèlich, contra Levi Strauss y otros, a una infancia de la humanidad. Pero la madurez sí existe, a mi juicio. La madurez de la humanidad sería la capacidad de cribar, comparar, analizar, sopesar, valorar y extraer las consecuencias de los distintos relatos, de las distintas tradiciones que nos constituyen y sustentan. Es una labor ardua y casi imposible, ya que como decía Gadamer para pensar necesitamos prejuicios y tal vez sea así, y no exista la posibilidad de esa ilustración ingenua, cartesiana, de un pensar neutro, absolutamente exterior. Pero sí es posible una comparación, un trabajoso sopesar. Se vive en la relación y se cambian o matizan las perspectivas y las posiciones, porque siempre estamos en lugares relativos, que aun siendo relativos, pueden cambiar y ampliar (o reducir) perspectivas y miradas.

\section{PEDAGOGÍA DE LA FINITUD}

Cabe, pues, esbozar una pedagogía de la finitud, consecuente con el carácter finito, contingente, inacabado de la existencia humana. El profesor Mèlich acude a lo antropológico para sustentar en ello, en su incierto suelo, una vacilante praxis pedagógica que es poética, literaria, narrativa en un sentido que conecta con planteamientos filosóficos próximos a Gadamer y sobre todo a Ricoeur (Kemp, 2006, 174-177). En la literatura se encuentran claves, según Mèlich, para el encuentro con las limitaciones espacio tempora- les del hombre, que sirvan para exorcizar la demonización que ocurre cuando lo relativo es elevado a absoluto, cuando lo relativo es, inapropiadamente, absolutizado, perdiendo su carácter contingente y pasando a ocupar como un todo el conjunto de lo real. Mèlich (2002) subraya la temporalidad y la memoria como parte de una pedagogía que resitúe en la metamorfosis a las personas. La literatura, en particular, nos reconcilia con nuestra consustancial finitud si aprendemos que hay tantas lecturas como lectores, que son posibles innumerables lecturas de un mismo texto porque el texto es algo inacabado, no logrado, finito, que nos transmite, por tanto, ese carácter antimetafísico que podemos extrapolar a la ética como relación con los otros, relación en perpetua reconsideración, como reconstitución con la alteridad desafiante (Mèlich, 2011).

En este discurso que enfatiza el desafío de la alteridad exteriorizante, lo que se señala es el papel de una negatividad impugnadora como tensión, el lugar de una dialéctica que pone el énfasis en lo no logrado, de lo que resta, de lo que no está, de lo ausente. Así, en una teoría del lenguaje, cobraría mayor importancia, por ejemplo, lo no dicho que lo dicho. Hay en el mundo, en la palabra, en la memoria, una serie de vacíos, de no lugares, que son también constituyentes, como magnitudes negativas, como densidades o presentes impresencias que una pedagogía de la finitud habrá de considerar y que, en términos morales, tienen que ver con la experiencia del mal, cuyo punto de máxima densidad ha sido Auschwitz (Mèlich, 2004b). Como afirma el profesor Reyes Mate: "Lo sorprendente de la memoria es que nos hace ver que de la realidad forma parte también algo que no existe" (Mate, 2003, 23).

Esta negatividad es la que se narra en el libro bíblico del Apocalipsis. En él el profesor Pérez Tapias encuentra expresada la necesidad de una radical solidaridad con los débiles, la lucha contra el mal y "el anhelo de que la muerte no obtenga la victoria, de que la injusticia no sea la última palabra" (Pérez Tapias 1999a, 87). Concluye el mencionado autor en el artículo al que nos referimos que "En esa tarea de un humanismo antiidolátrico debemos converger, desde la apuesta esperanzada en favor del hombre, en una historia tensa - ¿trágica sin remisión?- y siempre abierta" (Pérez Tapias 1999a, 88). Este mismo autor, en un artículo posterior propone retomar la concepción benjaminiana de la memoria y la recuperación del rostro del Otro maltratado, para relanzar el pensamiento utópico, tras su cuestionamiento en nuestros días de crisis de la Modernidad. Se trata de que a partir de lo 
fragmentario, retomemos una utopía abierta, sin afán de totalidad, que no sacrifique a los individuos a una identidad totalizante recayendo en totalitarismos (Pérez Tapias 1999b, 206-209).

El hombre concreto se hace en un movimiento centrípeto, por el que la tradición acude originando un centro que lo dota de una identidad, de la consistencia de ser Uno, sujeto o self. Esta tradición de símbolos y relatos es una alteridad fundante que ha cubierto la tiniebla original. Bien es cierto que esta tradición es ardua, compleja y enrevesada, y que aunque ofrece respuestas, también genera dudas $y$ nuevos interrogantes. Pero todo ello puebla, habita, llena, ocupa, pesa.

Por otro lado, con la instantaneidad de los acontecimientos puede ocurrir ese otro momento pedagógico del ver como por primera vez, del hacer una epojé de lo que se venía aceptando como normalidad y ser casi deslumbrados. Realmente, estos instantes provienen de algún contexto, de ese núcleo de la tradición. Emergen de ella. Porque nada surge del vacío, ninguna mirada humana mira en el vacío. Pero aun así se puede dar esa forma de ser deslumbrado en la que parece haber irrumpido una casi absoluta alteridad desafiante, algo que cuestiona, que como una fuerza centrífuga nos impulsa para abandonar el céntrico núcleo de la plena satisfacción (Mèlich, 2009, 142-144).

Este segundo movimiento "educativo" nos retrotrae a la precariedad inicial, a la vaciedad del origen, a un espacio por descubrir, a lo previo a la natalidad, poniéndonos de bruces ante la nada en la cual nos sustentamos y en la cual penden nuestras existencias. Nos arranca de lo céntrico, de lo denso, de lo grave. Nada de esto ocurre, obviamente, fuera del mundo, de la historia y de la materia. Hay que comprenderlo como dinámicas internas a los mismos, dadas dentro de ellos, en sus márgenes; no estamos hablando de un trascender en términos literales, aunque sí puede imaginarse una cierta anticipación analógica con lo que hipotéticamente Ilamaríamos lo sobrenatural. Es decir, hay en todo esto una cierta vitalidad, una energía, un avance, no necesariamente bueno ni malo en términos absolutos, sino un sencillo abandonar la falsa creencia de que todo empezaba y acababa en uno mismo.

Así pues, tenemos involucrado en la educación esto que hallamos en toda antropología: símbolos, relatos, finitud, alteridad, tiempo, historia, realidad. Pero ese instante crucial, reordena nuestro self. Ocurre como si se reestructurara lo que somos en unos segundos cru- ciales y entonces se ataran cabos sueltos. Una narración o persona brilla para nosotros como no brillan las demás, una vida nos impacta como ninguna otra, una historia habla con voz penetrante, imponiéndose. Se establece la mímesis creativa a la que se refiere Kemp en el colofón de su excelente artículo (2006, 183-184), la impronta que deja la auctoritas del maestro, fenómeno registrado y relatado a lo largo de nuestra tradición, que la filosofía hermenéutica recoge, como este autor indica en su trabajo.

En esos aconteceres reveladores, cuando podemos trazar una infalible lógica sobre el relato que uno viene siendo, cuando uno traza un argumento, cuando uno crea, somos verdaderamente educados. Nos alzamos sobre la tradición que somos y podemos analógicamente referirnos a una cierta forma de natalidad o infancia que el profesor Bárcena estudia y desarrolla en algunos trabajos desde una perspectiva propia y vinculada a la filosofía de Hannah Arendt (Bárcena, 2002). Es el momento poético por excelencia, el nacimiento de lo que podemos llamar más ahora que nunca "sujeto", que se hace, poéticamente, novedosamente, de este modo naciente, con los demás, vivos y muertos.

\section{CONCLUSIÓN: HACIA UNA PERSPECTIVA HERMENÉUTICA}

Recuerda el profesor Fernando Bárcena (2005, 1618) la diferencia griega establecida entre praxis y poiesis $^{2}$. Praxis, dice, como una actividad que se agota en sí misma, tiene su límite en sí misma y no implica una superación o trascendencia cualitativa alguna respecto a la propia actividad en sí. La poiesis, es una producción de algo nuevo, de un objeto cualitativamente diferenciado de la actividad que lo produce, creado, producido como un desbordamiento o como una superación del límite de la propia acción. La educación sería una praxis (actividad) productiva, en un sentido poético, de producción de algo nuevo, algo que viene a ser desde una no presencia, desde una previa impresencia, desde una nada originaria. Este acto creativo es lo que considera lo propiamente poético en la educación, la educación como donación de novedad, o como acontecer de novedad.

Así lo entienden, creo, Mèlich y Bárcena. El peligro positivista que denuncian y en lo que yo, en general, les doy la razón, es la confusión de este proceso de donación de novedad o actividad poética, creativa, con una tecnología o procedimiento o metodología (un cómo) de constitución de un producto (el resultado final, llámese educando, objetivos o competencias 
o sujeto competente). Hay una reducción instrumental de algo que es una actividad de naturaleza poética en un sentido originariamente griego de poiesis, de producción de algo nuevo que se hace presente, que irrumpe, que llega a estar con otros en la historia.

Señala Bárcena, más adelante, que lo que hay de novedad en ese acto creador es traicionado cuando se reduce a un mero aplicar un método establecido a priori, o sea, previamente a toda experiencia de la realidad dual, temporal, dinámica, singular como es propio del tiempo educativo. Un método no es ya un parto desde una cierta nada o impresencia, al estilo de una poiesis, una creación poética, sino que actúa como una cortina, velo o capa de ceniza que cubre la misteriosa singularidad que sucede o acontece en toda relación pedagógica. Hay una cegadora luminosidad que tapa la oscura ambigüedad de donde emerge el sujeto, donde se fabrica, poéticamente, el sujeto.

Esto hay quien lo entiende como si uno retrocediera a un ámbito pre-científico o anticientífico, lo cual no es cierto. Debe haber ciencia en la pedagogía, pero en el lugar que le corresponde, sin extralimitarse, sin ocupar ese tiempo previo, ese intervalo o espacio de la constitución creadora, del diálogo que se desarrolla en un hondo sentido más allá de lo meramente lógico, como algo en lo cual se juegan elementos muy serios, tales como la existencia del educando, su ser, su presencia pálida, en un mundo humanizado, acogida en la tarea de humanizar el mundo, de nombrar el mundo, de poetizar el mundo. Nada de esto se opone a que como parte de ese poetizar, como algo interno al poetizar, se haga ciencia. La ciencia en sí es también una pálida esfera, un deseo y un precario anhelo. Por esto, el estudioso de la educación puede y debe conocer científicamente lo que la ciencia sea capaz de decir de la educación, pero manteniendo esa humildad metafísica que estamos sugiriendo.

El problema que denunciamos es, por tanto, no que se aborden aspectos de la educación escolar o la educación en sí a partir de la ciencia, sino que la educación se reduzca a un proceso descriptible y abordable por métodos estrictamente positivos. Permanecer en un ámbito nihilizante manifiesta un cierto pathos, también, de lo etéreo que incluso a veces se asocia con dinámicas sociales de tipo burgués o intelectua- listas. Pero esto no se resuelve con la minuciosa microdescripción positivista de datos que desmenuza la realidad, atomizándola y, a mi juicio, desactivando la crítica que muchas veces se pretende ejercer con la teoría. La mirada proletaria, precisamente hoy, no es la del bombardeo del dato que halla contradicciones en la realidad o entre ella y la teoría, pues su efecto de hecho desactiva todo punto arquimédico desde el cual efectuar el movimiento de palanca de la crítica global.

Así, a pesar del riesgo que también implica, no debemos perder un cierto aire "intelectual" y "teorizante" en la pedagogía, para entender lo que sucede cuando educamos. Insisto que la educación es un acontecimiento, lo cual quiere decir que es siempre singular, inasible, personal, complejo, temporal, contingente. $Y$ esto no es captable empíricamente en su totalidad, no es posible comprenderlo de una manera que lo agote, sino que hay que probar distintas formas de hermenéutica, comprensivas, interpretativas, siempre abiertas e incluso literarias. Al menos así creemos que es, ciertamente, un sugerente modo de aproximación a lo que ocurre cuando educamos. La educación ostenta muchos elementos simbólicos y míticos, narrativos, en sus componentes y en su desarrollo, como algunas investigaciones recientes han sabido poner de manifiesto (Mateos y Núñez, 2011) o hace algún tiempo ha excelentemente expuesto algún trabajo teórico (García Amilburu, 2002).

Las complejas relaciones humanas que constituyen lo que llamamos educación hay que interpretarlas, captarlas en su multidimensionalidad; no son fácilmente explicables, son parte de un universo humanísimo de contagios, de símbolos y elecciones, de proyectos vitales; o sea, de algo muy serio, que, en su conjunto, llamamos educación o, tal vez, diría Martha Nussbaum al estilo estoico, "florecimiento" (Nussbaum, 2003). No todo ello es consciente, sino que en realidad es un proceso de situarse, de un colocarse en un "estar con", en un "donde", en un ámbito o mundo de la vida que se va originando y que orientará la propia existencia, un submundo que en gran medida será esa oscuridad ambigua e incierta que vamos siendo cada uno. 
1 En una investigación se ha puesto de relieve que en el paradigma pedagógico del service-learning se requiere una racionalidad de tipo práctico como la expresada por la phronesis aristotélica, frente a los modelos de conocimiento de tipo técnico o "epistémico" (Lukenchuk, 2009). Asimismo, el valor de la noción aristotélica de phronesis es abundantemente realzado en la literatura pedagógica, por sus

\section{BIBLIOGRAFÍA}

Adorno, Th. W. (2003). Minima moralia. Reflexiones desde la vida dañada. Madrid: Taurus. Edición original 1951.

Ayala, R. (2011). “La esperanza pedagógica: una mirada fresca y profunda a la experiencia educativa desde el enfoque de van Manem". Revista Española de Pedagogía, vol. 69, no 248, pp. 101-118.

Bárcena, F. (2002). "Educación y experiencia en el aprendizaje de lo nuevo". Revista española de pedagogía, no 223, pp. 501-520.

Bárcena, F. (2005). La experiencia reflexiva en educación. Barcelona: Paidós.

Beckett, D. (2008). "Holistic Competence: Putting Judgements First". Asia Pacific Education Review, vol. 9, no 1, pp. 21-30.

Beckett, D.; Agashae, Z. y Oliver, V. (2002). "Just-in-Time Training: Techne Meets Phronesis". Journal of Workplace Learning, vol. 14, no 8, pp. 332-339.

Berkeley, A. (2005). "Phronesis or Techne? Theatre Studies as Moral Agency". Research in Drama Education, vol. 10, no 2, pp. 213-227.

Bessant, J. (2009). "Aristotle Meets Youth Work: A Case for Virtue Ethics". Journal of Youth Studies, vol. 12, no 4, pp. 423-438.

Birmingham, C. (2003). "Practicing the Virtue of Reflection in an Unfamiliar Cultural Context". Theory into Practice, vol. 42, no 3, pp. 188-194.

Clark, Ch. (2005). "The Structure of Educational Research". British Educational Research Journal, vol. 31, no 3, pp. 289-308.

Egan, B. A. (2004). "Constructing a Professional Identity: Some Preliminary Findings From Students of Early Years Education". European Early Childhood Education Research Journal, vol. 12, no 2, pp. 21-32.

Esteban, J. (2002). Memoria, hermenéutica y educación. Madrid: Biblioteca Nueva. aplicaciones, tal como sugerimos en el cuerpo de nuestro trabajo. Vg. Beckett, Agashae y Oliver, 2002; Beckett, 2008. Se ha resaltado la necesidad de superación de un modelo técnico (techné) de pedagogía, lo cual implicaría adoptar la razón práctica que estamos propugnando (Berkeley, 2005; Smythe, MacCulloch y Charmley, 2009). Esto sería necesario para la toma de decisiones que involucran

Gadamer, H. G. (2002). Verdad y Método II. Salamanca: Sígueme. Edición original 1986.

Gadamer, H. G. (2003). Verdad y Método I. Salamanca: Sígueme. Edición original 1975.

García Amilburu, M. (2002). La educación, actividad interpretativa. Hermenéutica y Filosofía de la Educación. Madrid: Dykinson.

Gordillo, M. V. (1992). “El enfoque científico y la investigación en educación: la búsqueda de una nueva metodología". Revista Complutense de Educación, vol. 3, no 1-2, pp. 179-192.

Herrenkohl, L. R.; DeWater, L. S. y Kawasaki, K. (2010). "Teacher-Researcher Collaboration as a Human Science". Yearbook of the National Society for the Study of Education, vol. 109, no 1, pp. 207-221.

Horkheimer, M. y Adorno, Th. W. (2001). Dialéctica de la llustración. Fragmentos filosóficos. Madrid: Trotta. Edición original 1969.

Kemp, P. (2006). "Mimesis in Educational Hermeneutics". Educational Philosophy and Theory, vol. 38, no 2, pp. 171-184.

Levinas, E. (1977). Totalidad e infinito. Salamanca: Sígueme. (edición original 1971).

Lukenchuk, A. (2009). "Living the Ethics of Responsibility through University Service and Service-Learning: "Phronesis" and "Praxis" Reconsidered". Philosophical Studies in Education, 40, pp. 246-257.

Manem van, M. (1998). El tacto en la enseñanza. El significado de la sensibilidad pedagógica. Barcelona: Paidós.

Mate, R. (2003). Memoria de Auschwitz. Actualidad moral y política. Madrid: Trotta.

Mateos, T. y Núñez, L. (2011). “Narrativa y educación: Indagar la experiencia escolar a través de los relatos". Teoría de la Educación, vol. 23, no 2, pp. 111-128.

Mèlich, J. C. (2002). Filosofía de la finitud. Barcelona: Herder. aspectos morales en contextos interculturales (Birmingham, 2003) o sencillamente razonamientos morales (Bessant, 2009), o para el trabajo cooperativo entre los propios maestros (Herrenkohl, DeWater, y Kawasaki, 2010).

2 Estos conceptos griegos y su relevancia para la pedagogía son también expuestos en Egan, 2004
Mèlich, J. C. (2003). "La sabiduría de lo incierto. Sobre ética y educación desde un punto de vista literario". Educar, vol. 31, pp. 33-45.

Mèlich, J. C. (2004a). Antropología simbólica y acción educativa. Barcelona: Paidós.

Mèlich, J. C. (2004b). La lección de Auschwitz. Barcelona: Herder.

Mèlich, J. C. (2009). "Ética y narración”. ArsBrevis, pp. 136-150.

Mèlich, J. C. (2011). "Disonancias (Sobre ética y literatura)". ArsBrevis, pp. 97-115.

Nussbaum, M. C. (2003). La terapia del deseo. Teoría y práctica en la ética helenística. Barcelona: Paidós.

Pérez Luna, E. (2003). "La pedagogía que vendrá: Más allá de la cultura escolar positivista". Utopía y praxis latinoamericana. Revista Internacional de Filosofía Iberoamericana y Teoría Social, vol. 23, pp. 87-95.

Pérez Tapias, J. A. (1999a). “El 'aguijón apocalíptico' y la filosofía de la historia”. Diálogo filosófico, vol. 43, pp. 71-88.

Pérez Tapias, J. A. (1999b). "Cambio de paradigma en el pensar utópico". Diálogo filosófico, vol. 44, pp. 180-210.

Smythe, E. A.; MacCulloch, T. y Charmley, R. (2009). "Professional Supervision: Trusting the Wisdom that 'Comes'”. British Journal of Guidance and Counselling, vol. 37, no 1, pp. 17-25.

VanderVen, K. (2009). "If theory and practice were the same, then what? A new approach to designing professional education". Child and Youth Services, vol. 31, no 3-4, pp. 188-212.

Zamora, J. A. (2009). "Th. W. Adorno: Aportaciones para una Teoría Crítica de la educación". Teoría de la Educación, vol. 21, no 1, pp. 19-48. 